\title{
Evaluating the Conservative Management of Blunt Abdominal Trauma; a Prospective Study
}

\author{
Mohamed A Nada, ${ }^{1}$ MD; Hatem Elgohary, ${ }^{2}$ MD, MRCS; Ramadan A Abou-Ahmed, ${ }^{3}$ MSc \\ ${ }^{1}$ Department of General Surgery, Ain Shams University \\ 2Department of General Surgery, Helwan University \\ ${ }^{3}$ Department of General Surgery, Kafr El Shikh General Hospital, Ministry of Health
}

Background: Trauma is the commonest cause of death in age group between 1 and 44 years and comes in the third place regardless to the age, early detection of intra-abdominal injuries is crucial and improper management will lead to significant morbidity or even mortality. Conservative treatment is the first choice for blunt abdominal traumas as $80 \%$ of liver injuries, more than $50 \%$ of splenic injuries and virtually almost all renal injuries are managed non-operatively. Our objective from this study was to evaluate the effectiveness of conservative management of injuries due to blunt abdominal trauma.

Patients and methods: This was a prospective study including 100 patients who were admitted to the emergency departments in three institutes between October 2011 and October 2014 with blunt abdominal trauma. We included patients with blunt abdominal trauma who were haemodynamically stable at the time of presentation or became haemodynamically stable after proper resuscitation.

Results: Mean age of patients was 28.9 years and a road traffic accident was the cause in $69 \%$ of patients. The overall success rate in the study was $94 \%$ which included liver injuries with a success rate of $100 \%$ and splenic injuries with a success rate of $92.4 \%$.

Conclusion: Non operative management showed good success rates for stable patients with blunt abdominal trauma affecting solid organs.

Key words: Trauma, conservative management, abdominal injuries.

\section{Introduction}

Trauma is the commonest cause of death in the age group between 1 and 44 years and comes in the third place regardless to the age. ${ }^{1}$ It is known that $10 \%$ of trauma deaths results from abdominal injuries which may be blunt in $84 \%$ of cases and the most commonly injured organs are liver, spleen, kidney, small bowel, diaphragm, urinary bladder and the pancreas. ${ }^{2}$

Blunt abdominal trauma could be evaluated properly by focused abdominal assessment with sonography for trauma (FAST). ${ }^{1}$ Although FAST is sensitive for detecting intraperitoneal free fluid of more than $250 \mathrm{ml}$, it is not reliable in determining the source of bleeding or in grading solid organ injuries. $^{3}$

CT scan is the investigation of choice for evaluating hemodynamically stable patients with blunt abdominal trauma injuries. It provides accurate imaging of the abdominal viscera, retroperitoneum and abdominal wall. Moreover, it is very helpful in the follow up of patients who are managed conservatively. ${ }^{4,5}$ In addition, CT scan with contrast is highly sensitive in grading solid organ injuries (Tables 1,2). ${ }^{6}$

Table 1: Liver injury grading scale ${ }^{6}$

\begin{tabular}{lll}
\hline Grade* & Type & Description of injury \\
\hline I & Hematoma & Subcapsular, $<10 \%$ surface area \\
& Laceration & Capsular tear, $<1 \mathrm{~cm}$ parenchymal depth \\
II & $\begin{array}{l}\text { Hematoma } \\
\text { Laceration }\end{array}$ & $\begin{array}{l}\text { Subcapsular, } 10 \% \text { to } 50 \% \text { surface area; intraparenchymal, }<5 \mathrm{~cm} \text { in diameter } \\
\text { Capsular tear, } 1-3 \mathrm{~cm} \text { parenchymal depth that does not involve a trabecular vessel }\end{array}$ \\
III & Hematoma & $\begin{array}{l}\text { Subcapsular, }>50 \% \text { surface area or expanding; ruptured subcapsular or parenchymal he- } \\
\text { matoma; intraparenchymal hematoma } \geq 5 \mathrm{~cm} \text { or expanding }\end{array}$ \\
& Laceration & $\begin{array}{l}\text { Parenchymal depth }>3 \mathrm{~cm} \text { or involving trabecular vessels } \\
\text { IV }\end{array}$ \\
Laceration & $\begin{array}{l}\text { Laceration involving segmental or hilar vessels producing major devascularization }(>25 \% \text { of } \\
\text { liver) }\end{array}$ \\
V & Laceration & Completely shattered liver \\
Vascular & Hilar vascular injury that devascularizes liver \\
\hline
\end{tabular}


Table 2: Splenic injury grading scale ${ }^{6}$

\begin{tabular}{|c|c|c|}
\hline Grade* & Type & Description of injury \\
\hline \multirow{2}{*}{ I } & Hematoma & Subcapsular, $<10 \%$ surface area \\
\hline & Laceration & Capsular tear, $<1 \mathrm{~cm}$ parenchymal depth \\
\hline \multirow{2}{*}{ II } & Hematoma & Subcapsular, $10 \%$ to $50 \%$ surface area; intraparenchymal, $<5 \mathrm{~cm}$ in diameter \\
\hline & Laceration & Capsular tear, $1-3 \mathrm{~cm}$ parenchymal depth that does not involve a trabecular vessel \\
\hline \multirow[t]{2}{*}{ III } & Hematoma & $\begin{array}{l}\text { Subcapsular, }>50 \% \text { surface area or expanding; ruptured subcapsular or parenchymal he- } \\
\text { matoma; intraparenchymal hematoma } \geq 5 \mathrm{~cm} \text { or expanding }\end{array}$ \\
\hline & Laceration & Parenchymal depth $>3 \mathrm{~cm}$ or involving trabecular vessels \\
\hline IV & Laceration & $\begin{array}{l}\text { Laceration involving segmental or hilar vessels producing major devascularization ( }>25 \% \text { of } \\
\text { spleen) }\end{array}$ \\
\hline \multirow{2}{*}{$\mathrm{V}$} & Laceration & Completely shattered spleen \\
\hline & Vascular & Hilar vascular injury that devascularizes spleen \\
\hline
\end{tabular}

Early detection of intra-abdominal injuries is crucial in its management and with failed or delayed detection improper management will lead to significant morbidity or even mortality. ${ }^{7}$

Conservative treatment is the first choice for blunt abdominal traumas as $80 \%$ of liver injuries, more than $50 \%$ of splenic injuries and virtually all renal injuries are managed non-operatively, this is inclusively for hemodynamicallystable patients or patientswhosustained haemodynamicstability after primary resuscitation. ${ }^{8}$

The aim of this study was to evaluate the conservative management for stable or easily stabilized blunt abdominal trauma patients and to assess the success rates hoping to establish a patient's categorization for conservative management in our institute.

\section{Patients and methods}

This was a prospective study including 100 patients admitted with blunt abdominal trauma to the emergency departments of Ain Shams University Hospitals, Dar El Shefa Hospital and Kafr El Shikh General Hospital between October 2011 and October 2014. This study was approved from the ethical and scientific committee, General Surgery Department, Ain-Shams University, we included patients with blunt abdominal trauma who were haemodynamically stable at the time of presentation or became haemodynamically stable after proper resuscitation.

We applied the ATLS protocol of management to unstable polytraumatized patients in the form of; securing the airway, control of breathing and ventilation, control of circulation, assessment of neurological status and proper exposure.

On admission, blood sample was sent for complete blood count (CBC), liver profile (SGOT, SGPT), kidney profile (creatinine, BUN), blood grouping and cross matching, patients were examined by focused abdominal sonography for trauma (FAST). Patients with positive FAST were further investigated by pelviabdominal CT scan with IV and oral contrasts.

The American Association for the Surgery of Trauma (AAST) grading scale (CT grading system of solid organ injuries) was applied. ${ }^{6}$

Patients who were stable with documented liver or splenic injury were included in the study and they were managed conservatively. While patients with negative FAST, those with frank indication necessitating urgent surgical intervention and patients with Glasgow coma Score $\leq 12$ after proper primary resuscitation were excluded from the study. Moreover, patients on oral anticoagulation drugs and patients with liver cirrhosis documented by FAST were also excluded.

For patients with positive FAST and no solid organ injuries detected by CT scan examination, ultrasound guided peritoneal aspiration was done to identify the nature of the free fluid (serous, sero-sanguineous or blood).

All patients who were managed conservatively were kept under observation for the next 48 hours where pelviabdominal CT scan was repeated to ensure no further bleeding.

Conservative management included IV fluids resuscitation, close observation of the vital signs, monitoring urine output, and blood transfusion if needed, urgent laparotomy was done to patients with failed conservative management which was defined as any rapid drop in the vital signs (pulse and blood pressure), drop in the hemoglobin $\%$ or significant increase in the volume of hemoperitoneum in repeated FAST (if needed). 
Patients with succeeded conservative management were instructed before discharge to revisit the ER department if they had any disturbed level of consciousness, vomiting or abdominal pain.

Patients were followed up once per week in the outpatients clinic for 3 months and abdominal CT scan was repeated 6 weeks following the trauma.

\section{Statistical analysis}

Data were collected, revised, coded and entered to the Statistical Package for Social Science (IBM SPSS) version 20. Qualitative data were presented as numbers and percentages while quantitative data were presented as mean standard deviations and ranges. Comparisons between groups with qualitative data were done by using Chi-Square test. The confidence interval was set to $95 \%$ and the margin of error accepted was set to $5 \%$. So, the $p$-value was considered significant at the level of $<0.05$.

\section{Results}

- This study involved 100 patients (75 males and 25 females) having a mean age of 28.9 years (range 8-66yrs, mean 28.9 and SD 22.1) (Figure 1). The mechanism of blunt trauma was road traffic accident in $69 \%$, physical assault in $25 \%$ and falling from height in $6 \%$.

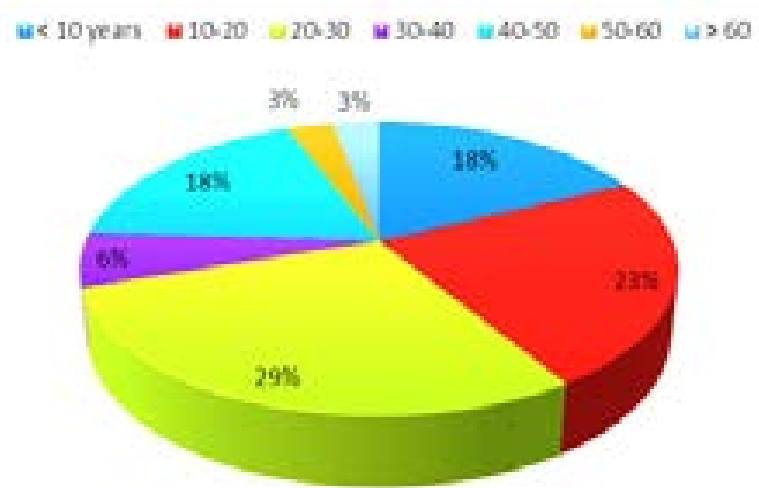

Fig 1: Age distribution of the studied patients.
- Non-operative management was applied to all patients that were included in the study, about $42(42 \%)$ of them were haemodynamically stable on admission and the rest 58 patients $(58 \%)$ were haemodynamically unstable.

- The results of FAST and CT scan showed that 72 patients $(72 \%)$ had splenic injuries, 20 (20\%) had liver injuries, 7 (7\%) had combined splenic and liver injuries, and only one patient (1\%) had haemoperitoneum without solid organ injuries.

- $\quad$ Splenic injuries were in the form of lacerations in 54 patients $(68.35 \%)$ and hematomas in 25 patients $(31.65 \%)$, grades of splenic lacerations and hematomas are shown in Table 3.

- Liver injuries were in the form of lacerations in 15 patients (55.6\%) and hematomas in 12 patients (44.4\%). Grades of liver lacerations and hematomas are shown in Table 4.

- $\quad$ The overall success rate in the study was $94 \%$ which included liver injuries with success rate of $100 \%$ and splenic injuries with success rate of $92 \%$.

- $\quad$ Our results showed that all patients with splenic hematomas were managed conservatively, whereas six patients with lacerations (11.11\%) required laparotomy ( $P$ value 0.048 ).

- The follow-up abdominal CT scan after 6 weeks showed complete resolution of the previously reported organ injuries in all patients $(n=94)$.

Table 3: Grades of splenic lacerations and hematomas

\begin{tabular}{lcccc}
\hline & Grade I number & Grade II number & Grade III number & Grade IV number \\
& $\mathbf{\&}(\%)$ & $\mathbf{\&}(\%)$ & $\mathbf{\&}(\%)$ & \& (\%) \\
\hline $\begin{array}{l}\text { Spleniclaceration }(\mathrm{n}=54) \\
\begin{array}{l}\text { Splenic haematoma } \\
(\mathrm{n}=25)\end{array}\end{array}$ & $9(16.67 \%)$ & $27(50 \%)$ & $9(16.67 \%)$ & $9(16.67 \%)$ \\
\hline
\end{tabular}


Table 4: Grades of liver lacerations and hematomas

\begin{tabular}{lcccc}
\hline & $\begin{array}{c}\text { Grade I number } \\
\mathbf{\&}(\%)\end{array}$ & $\begin{array}{c}\text { Grade II number } \\
\mathbf{\& ( \% )}\end{array}$ & $\begin{array}{c}\text { Grade III number } \\
\mathbf{\&}(\%)\end{array}$ & $\begin{array}{c}\text { Grade IV number } \\
\mathbf{\&}(\%)\end{array}$ \\
\hline Hepatic laceration & $0(0 \%)$ & $12(80 \%)$ & $3(20 \%)$ & $0(0 \%)$ \\
Hepatic haematoma & $0(0 \%)$ & $9(75 \%)$ & $3(25 \%)$ & $0(0 \%)$ \\
\hline
\end{tabular}

Table 5: The outcome of the conservative management according to the ageby $y r s .(P>0.05)$

\begin{tabular}{ccc}
\hline Age by years & $\begin{array}{c}\text { Succeeded conservative } \\
\text { management (n: 94) }\end{array}$ & $\begin{array}{c}\text { Failed conservative } \\
\text { management (n: 6) }\end{array}$ \\
\hline$\leq 10$ & $18(19.1 \%)$ & 0 \\
$>10$ to 20 & $23(24.5 \%)$ & 0 \\
$>20$ to 30 & $29(30.9 \%)$ & 0 \\
$>30$ to 40 & $5(3.2 \%)$ & $1(16.7 \%)$ \\
$>40$ to 50 & $16(17.0 \%)$ & $2(33.3 \%)$ \\
$>50$ to 60 & $2(2.1 \%)$ & $1(16.7 \%)$ \\
$>60$ & $1(1.1 \%)$ & $2(33.3 \%)$ \\
\hline
\end{tabular}

Table 6: Mechanism of injury and the outcome of the conservative management. $(P>0.05)$

\begin{tabular}{ccc}
\hline Mechanism of injury & $\begin{array}{c}\text { Succeeded conservative } \\
\text { management (n: 94) }\end{array}$ & $\begin{array}{c}\text { Failed conservative } \\
\text { management (n:6) }\end{array}$ \\
\hline Road traffic accident & $67(71.3 \%)$ & $2(33.3 \%)$ \\
Physical assault & $21(22.3 \%)$ & $4(66.7 \%)$ \\
Fall from height & $6(6.4 \%)$ & 0 \\
\hline
\end{tabular}

Table 7: Outcome of conservative management and grade of splenic lacerations $(P<0.05)$

\begin{tabular}{ccc}
\hline & $\begin{array}{c}\text { Succeeded conservative } \\
\text { management (n:48) }\end{array}$ & $\begin{array}{c}\text { Failed conservative } \\
\text { management (n:6) }\end{array}$ \\
\hline Grade I & $9(18.8 \%)$ & None \\
Grade II & $27(56.3 \%)$ & None \\
Grade III & $8(16.7 \%)$ & $1(16.7 \%)$ \\
Grade IV & $4(8.3 \%)$ & $5(83.3 \%)$ \\
\hline
\end{tabular}




\section{Discussion}

After analysis of the data and results in our study, we found that $58 \%$ of the studied patients were between 10 and 40 years. And this is consistent with the fact that trauma is the leading cause of death between the age of 1 and 44 years. ${ }^{9}$

In our study, though there were high failure rates in elderly patients, yet it was found insignificant $(P>0.05)$ but as 5 out of the 6 failures were older than 40 years we are convinced that failure of conservative management is positively related to elderly traumatized patients. Fang et al, reported a similar finding and they concluded that elderly had unfavorable outcomes of non-operative management. ${ }^{10}$

The most common mechanism was the road traffic accidents which were represented in about $69 \%$ of all patients. These included vehicle versus vehicle, vehicle versus pedestrian and motor cycle accidents, it was reported that road traffic accidents represent $80.95 \%$ in the developed countries. ${ }^{11}$

It has been reported that the CT scan is very sensitive in differentiating different forms of solid organ injuries in stable patients with blunt abdominal trauma. ${ }^{12}$

Splenic injury was the most dominant form of injuries, accounting for about $72 \%$ of injuries in our patients, whereas $20 \%$ were due to solitary liver injury, $7 \%$ due to combined liver and splenic injuries and $1 \%$ was due to hemoperitoneium without solid organs injuries. In few studies, liver injuries were reported to be the most common solid organ injury due to blunt abdominal trauma, however the majority of studies reported splenic injury to be the commonest. ${ }^{13}$

Overall, in our study, the success rate of conservative management was $92.4 \%$ for splenic injuries and $100 \%$ for liver injuries. Hoff et al., mentioned that greater than $95 \%$ of solid organs injures may be managed without surgical intervention and with similar or lower complication rates compared with operative management. ${ }^{14}$ Similar results with 60 $80 \%$ of blunt splenic injuries and $85-98 \%$ of hepatic injuries that were managed non-operatively with success rates approaching $95 \%$ were reported. ${ }^{15,16}$

The controversy was reported by Schroeppel and Croce when they found that non-operative management of liver injuries is associated with higher morbidity than splenic injuries. ${ }^{17}$

Bouras \& co-workers concluded that around $85 \%$ of patients with blunt hepatic trauma are stable following resuscitation and in this group, the nonoperative management has been shown to be superior to laparotomy in avoiding complications and decreasing mortality. ${ }^{18}$

All cases with failed conservative management had high grade splenic laceration (grade IV) except one case that had grade III splenic laceration $(P<0.05)$. This was reported by Santucci et al, ${ }^{19}$ and Kozar et al. ${ }^{20}$ They concluded that non-operative management may be employed for all grades of splenic, hepatic and renal injuries but higher grades are associated with an increased failure rates and more complications.

We faced many cases of higher grades splenic and liver injuries but patients were hemodynamically unstable and resuscitation protocols failed, therefore they were subjected to laparotomy from the start and were excluded from the study.

\section{References}

1. Burch JM, Franciose RJ, Moore EE: Trauma. Principles of Surgery $7^{\text {th }}$ ed 1999; 6: 155-223.

2. Soynucu S, Cete $Y$, Bozan H, Kartal M, Akyol AJ: Accuracy of physical and ultrasonographic examination by emergency physicians for the early diagnosis of intra-abdominal haemorrhage in blunt abdominal trauma. Injury 2007; 38: 564-569.

3. Chong C, Wang T, Chang H: Evaluation of blunt abdominal trauma: current practice in Taiwan. Emerg Med J 2005; 22: 113-115.

4. Hassan R, Abd Aziz A: Computed tomography (CT) imaging of injuries from blunt abdominal trauma: A pictorial essay. Malaysian J Med Sci 2010; $17: 29-39$.

5. Elton $C$, Riaz $A A$, Young $N$, Schamschula $\mathrm{R}$, Papadopoulos $B$, Malka V: Accuracy of computed tomography in the detection of blunt bowel and mesenteric injuries. Br J Surg 2005; 92 :1024-1028.

6. Moore EE, Cogbill TH, Malangoni M, Jurkovich GJ, Shackford SR, Champion HR, McAninch JW: Organ injury scaling. Surg Cli N Am 1995; 75: 293-303.

7. Bourguignon $P R$, Shackford $S R$, Shiffer C,Nichols P, Nees AV: Delayed fluid resuscitation of head injury and uncontrolled hemorrhagic shock. Arch Surg 1998; 133 :390-398.

8. Aecher L, Rogers F, Shackford SR: Selective non operative management of liver and spleen injuries in neurological impaired adult patients. Arch Surg 1996; 131 :309-415. 
9. Heron M: Deaths: Leading causes for 2014. National Vital Statistics Reports 2016; 65: 1-96.

10. Fang JF, Chen RJ, Lin BC, Hsu YB, Kao JL, Chen MF: Liver cirrhosis: An unfavorable factor for nonoperative management of blunt splenic injury. J Trauma 2003; 54: 1131-1136.

11. McGahan JP, Richards J, Fogata MLC: Emergency ultrasound in trauma patients. Radiol Clin N Am 2004; 42: 417-425.

12. El Wakeel AM, Habib RM, Ali AN: Role of CT in evaluation of blunt abdominal trauma. Int $\boldsymbol{J}$ Med Imag 2015; 3:89-93.

13. Fisher RP, Miller-Crotchett $P$, Reed RL: Gastrointestinal disruption: The hazard of nonoperative management in adults with blunt abdominal injury. J Trauma 1998; 28: 14451449.

14. Hoff WS, Holevar M, Nagy KK, Patterson L, Young JS, Najarian MP, Valenziano CP: Practice management guidelines for the evaluation of blunt abdominal trauma: The East practice management guidelines work group. $\boldsymbol{J}$ Trauma 2002; 53: 602-615.
15. Velmahos GC, Toutouzas K, Radian R, Chan L, Rhee P, Tillou A, Demetriades D: High success with non-operative management of blunt hepatic trauma: The liver is a sturdy organ. Arch Surg 2003; 138: 475-481.

16. Bernardo GC, Fuster J, Bombuy E, Sanchez S, Ferrer J, Loera MA, Marti J, Fondevila C, Zavala E, Garcia-Valdecasas JC: Treatment of liver trauma: operative or conservative management. Gasterentrol Res 2010; 3: 9-18.

17. Schroeppel TJ, Croce MA: Diagnosis and management of blunt abdominal solid organ injury. Curr Opin Crit Care 2007; 13: 399-404.

18. Bouras AF, Truant S, Pruvot FR: Management of blunt hepatic trauma. J Visc Surg 2010; 147: $351-358$

19. Santucci RA, Langenburg SE, Zachareas MJ: Traumatic haematuria in children can be evaluated as in adults. $\boldsymbol{J}$ Urol 2004;171:822825.

20. Kozar RA, Moore JB, Niles SE, Holcomb JB, Moore EE, Cothren CC, Hartwell E, Moore FA: Complications of nonoperative management of high-grade blunt hepatic injuries. J Trauma 2005; 59 :1066-1071. 